\title{
Natural Stones: architectonic heritage and its global relevance
}

\author{
${ }^{1}$ Department of Geology, Panjab University, Chandigarh-160014, India; *Corresponding author, E-mail: gurmeet28374@gmail.com \\ ${ }^{2}$ MHB Geological Services, Rua Turiassu 446, 05005-000, São Paulo \\ ${ }^{3}$ Department of Geology, Plaza de la Merced s/n, University of Salamanca, 37008 Salamanca, Spain
}

(Received: January 20, 2021; Revised accepted: January 20, 2021)

https://doi.org/10.18814/epiiugs/2020/0200s 15

This special issue of Episodes is dedicated to heritage stones. The heritage stones stand a good chance of designation as 'Global Heritage Stone Resource’ by International Union of Geological Sciences (IUGS) on basis of their geological and architectural attributes, status of preservation and survival of historical quarries and current upkeep of the stone built heritage (https://globalheritagestone. com/reportsand-documents/terms-of-reference/). This special issue in Episodes is the second issue on heritage stones, the first being published in 2015. The natural stones and rocks have a profound impact on the evolution of humanity. The natural cave dwellings, stone tools for hunting to magnificent monuments are few examples of how the story of stones evolved. The natural stones have always been an integral part of different cultures around the globe. The initiative of designating the natural stones as Global Heritage Stones Resource by the IUGS is unique and the patrons are all the nations which are dotted with stone-built monuments of cultural significance. The European stones predominate the list of designated GHSRs whereas the other stakeholders around the globe are way behind in promoting their stone-built architectural and cultural heritage. The need of the hour is to bring out this special issue on natural stones to promote the idea to all the nations to come up with the documentation of the stones used in their monuments, the state of preservation of historical quarries, the record and strategy adopted for the upkeep of monuments and the historical quarries. Perhaps IUGS Heritage Stone Subcommission (HSS) is a pioneering body which has been designating stones of historical and cultural significance from different continents as Global Heritage Stone Resource (GHSR) based on certain criteria defined in the Terms of Reference of the Subcommission (https://globalheritagestone.com/ reports-and-documents/terms-of-reference/). The main objective of this special issue is to keep advancing on the HSS initiative and add more stones from other countries in the list of designations (Pereira, 2019; Kaur et al., 2020).

This special issue contains six papers pertaining to the theme of this SI promoting the natural stones of Brazil, France, India, Qatar and Spain. Cárdenes et al. (2021) review the historical meaning and petrophysical characteristics of a roofing slate from Bernardos, one of Spain's flagship dimension stones that has a long history and representativeness in some of the most important Spanish heritage buildings and monuments erected from the $16^{\text {th }}$ to $19^{\text {th }}$ centuries. Pereira et al. (2021) report the economic importance of granite quarrying in Spain and highlight their role in restoration of architectural heritage. The Azul Platino, a bluish variety of granite of the Plasenzuela pluton that has been used in local, national and international projects, is presented as an example of such application. Sreejith et al. (2021) describe Charnockite, an international important stone that is used worldwide, both in heritage built on stone and contemporaneous architecture. The authors based their study on Indian and Brazilian charnockites, with well-known examples of historical buildings and monuments built on this stone in India and Brazil in particular and elsewhere in the world. Ballesteros et al. (2021) describe a coccolithic limestone used in Normandy, mainly during Medieval times, to build traditional architecture. This Normandy chalkstone is fully presented, with stratigraphic, petrographic and geochemical data that will improve the knowledge of this important stone worldwide. Freire-Lista et al. (2021) studied several types of limestones traditionally used for building mosques, houses and sheds in the Fuwairit archaeological site (NE Qatar). Looking for this heritage site conservation, thermal expansion measures were carried out to investigate the breakage of the Umm Bab Member of the Dammam Formation (Middle Eocene) when compared to Pleistocene oolites, also used in these constructions. Castro et al. (2021) describe a typical Brazilian rock used profusely in Rio de Janeiro to build the metropolis, but also some of the most important natural geoheritage sites such as the Corcovado and the Sugar Loaf. The deterioration of this rock in some of the buildings makes especially important the availability of the quarries to face restoration actions of these buildings to preserve the integrity of Rio de Janeiro's built heritage. This special issue also includes an exhaustive report on the IGCP Project-637 prepared by Pereira (2021).

\section{Acknowledgements}

The Guest Editors GK, MH and DP greatly appreciate the support of Editor-in-Chief Prof. Dr. Jin-Yong Lee and Managing Editor Heejung Kim for completion of this special issue. We appreciate the timely submission of manuscripts by authors for this SI. We place on record a deep sense of gratitude towards all the reviewers for adhering to the time frame for reviews. The IUGS and Publications Committee of Episodes are greatly acknowledged for granting us the permission to publish this SI in Episodes. 


\section{References}

Ballesteros, D., Painchault, A., Nehme, C., Todisco, D., Varano, M., and Mouralis, D., 2021, Normandy chalkstone (France): geology and historical uses from quarries to monuments, Episodes, v. 44, pp. 31-42.

Cárdenes, V., Rubio, A., and Ruiz de Argandoña, V.G., 2021, Roofing slate from Bernardos, Spain: a potential candidate for global heritage stone, Episodes, v. 44, pp. 3-9.

Castro, N.F., Mansur, K.L., Frascá, M.H.B.O., and Silva, R.E.C., 2021, Heritage stone of Rio de Janeiro (Brazil): the Facoidal gneiss, Episodes, v. 44, pp. 59-74.

Freire-Lista, D.M., Sousa, L., Carter, R., and Al-Na‘īmī, F. 2021, Petrographic and petrophysical characterisation and structural function of the heritage stones in Fuwairit archaeological site (NE Qatar): implica- tions for heritage conservation, Episodes, v. 44, pp. 43-58.

Kaur, G., Singh, S.N., Ahuja, A., and Singh, N.D., 2020, Natural Stone and World Heritage: Delhi-Agra, India. CRC Press.

Pereira, D., Tejado, J.J., Mota, M.I., 2021, Azul Platino: a bluish granite from Extremadura (Spain) to be considered in the context of architectural heritage, Episodes, v. 44, pp. 11-17.

Pereira, D., 2019, Natural Stone and World Heritage: Salamanca (Spain). CRC Press.

Pereira, D., 2021, Final report of IGCP-637: a project linking researchers and heritage stones from around the world, Episodes, v. 44, pp. 75-80.

Sreejith, C., Lama, E.A.D., and Kaur, G., 2021, Charnockite: a candidate for 'Global Heritage Stone Resource' designation from India, Episodes, v. 44 , pp. $19-29$.

https://globalheritagestone.com/reports-and-documents/terms-of-reference/ 